\title{
Role of three dimensional ultrasound in uterine anomalies - 3D assessment of cervix in septate uteri
}

\author{
Selvaraj Ravi Lakshmy*, Nity Rose, Meenakshi Ramachandran
}

Shri Lakshmi Scan Centre, 185/386-A, Govindhachetty Street, NCR Complex, Kaveripattinam - 635112, Krishnagiri, Tamilnadu, India

Received: 20 August 2016

Accepted: 15 September 2016

\section{*Correspondence:}

Dr. Selvaraj Ravi Lakshmy,

E-mail: drlakshmiravi@gmail.com

Copyright: ( $)$ the author(s), publisher and licensee Medip Academy. This is an open-access article distributed under the terms of the Creative Commons Attribution Non-Commercial License, which permits unrestricted non-commercial use, distribution, and reproduction in any medium, provided the original work is properly cited.

\begin{abstract}
Background: Mullerian duct anomalies are associated with higher incidence of infertility, recurrent pregnancy loss and fetal complications. The role of imaging is to distinguish between surgically correctable forms of mullerian duct anomalies from the inoperable forms. HSG and 2D ultrasound does not give a definitive diagnosis in double uterine cavity anomalies and moreover septate uterus with double ostia can be misinterpreted as unicornuate uterus on HSG as the dye passes through only one ostium. The study highlights the usage of transvaginal 3D ultrasound in assessment of the cervix in septate uterus.

Methods: Volume acquisition was obtained in the sagittal section of uterus by transvaginal route. Under adequate magnification care was taken to include the cervix and then the volume was acquired. The rendering box was adjusted and the green line placed in the region of cervix to get the satisfactory transverse rendered image of cervix.

Results: 3D assessment of cervix in 44 septate uterus revealed single cervical ostium in 36, complete septum with double ostia in 8 cases of which one had a duplicated cervix. There was absolute correlation between 3D assessment of the cervix and clinical evaluation.

Conclusions: 3D transvaginal ultrasonography of the uterine cavity is extremely accurate in diagnosing and classifying anomalies. Assessment of double uterine cavity abnormalities is complete with 3D evaluation of cervix. The added advantage of assessing cervix with 3D helps to distinguish between single and double ostia in septate cervix.
\end{abstract}

Keywords: Congenital uterine anomalies, Septate uterus, 3 Dimensional ultrasound, Cervical assessment

\section{INTRODUCTION}

Congenital uterine malformations are a heterogeneous group of anomalies with a broad spectrum of presentations. Defective development of mullerian duct either during fusion or during septal resorption results in uterine anomalies. They may be found incidentally, or during work up for infertility and recurrent pregnancy loss. The estimated prevalence is $0.4 \%(0.1-3 \%)$ in the general population, $13.3 \%$ in infertile patients and between $3 \%$ and $38 \%$ in patients with repeated spontaneous miscarriages. ${ }^{1}$
Congenital uterine anomalies may be initially suspected with two dimensional ultrasonography (2D US) or on hysterosalpingography (HSG) done at routine infertility workup. Both HSG and MRI (Magnetic resonance imaging) are gold standards in confirming the diagnosis but have their own limitations. High rates of recurrent pregnancy loss both in first trimester $(25 \%)$ and in mid trimester $(6 \%)$ have been associated with septate uterus. ${ }^{2}$ Recurrent miscarriage in these patients are due to implantation of the embryo onto a poorly vascularized septum. Though it is associated with the worst pregnancy outcome, it is the most amenable to surgical correction. ${ }^{2,3}$ 
Management options vary in septate uterus depending on the presence of septum or a duplicated cervix. The former one can be surgically corrected by hysteroscopic septal resection whereas the latter is corrected by a septal resection with unification of cervix. ${ }^{4}$ Hence, correct assessment of cervix in septate uterus becomes vital for its management. This paper is a review showing different forms of mullerian anomalies depicted clearly on transvaginal three dimensional ultrasound (3D US) with 3D assessment of cervix. Single or double ostia in double uterine cavity anomalies can be accurately diagnosed with a transvaginal 3D ultrasound.

\section{METHODS}

Women in the reproductive age group who were referred to our ultrasound clinic for routine pelvic scan, infertility workup and evaluation for recurrent pregnancy loss were included in the study. Transabdominal and 3D transvaginal evaluation of uterus was done to detect uterine anomalies after obtaining informed consent from them. Examinations were performed using GE Voluson 730 Pro and Voluson E8 machine by a single operator. Transvaginal 3D assessment of cervix was done in cases of septate uterus. Under adequate magnification the volume was obtained in the sagittal section from one side of the uterus to the other. Care was taken to include the cervix during volume acquisition. The volumes were manipulated until a satisfactory image of the cervix was obtained and the rendering box was adjusted as shown in Figure 1a to obtain a transverse view of the cervix. Longitudinal rendered image of the cervix could be obtained by placing the rendering line on the endometrial cavity as shown in Figure 1b. The same can be done in real time with $4 \mathrm{D}$ evaluation.

\section{RESULTS}

87 cases of uterine anomalies were identified of which $30 \%$ had come for infertility evaluation, $10 \%$ had been incidentally detected and the remaining $60 \%$ had come for evaluation of recurrent pregnancy loss. Seven patients with uterine anomalies had been detected at the time of early pregnancy scans. With the help of 3D transvaginal scanning, the uterine anomalies were classified as follows.15 of them were diagnosed as arcuate uterus, 17 as bicornuate uterus, 4 as unicornuate uterus and the remaining 44 were diagnosed as septate uterus. In 17 bicornuate uteri, 5 of them were associated with rudimentary horn and 12 had equally well developed horns

3D assessment of cervix was done in 44 cases of septate uterus. Figure 2 is an illustration of four cases of septate uteri with their corresponding cervix. 33 of them had a single cervical ostium with the uterine septum extending from the uterine fundus to varying lengths into the uterine cavity (Figures $2 \mathrm{a}$ and $\mathrm{b}$ ). A complete septum extending up to the cervix splits the cervical canal into two and the cervix has double ostia. 11 cases were identified to have a complete septum with double ostia (Figure 2c). One out of the 11 had a duplicated cervix which is illustrated in Figure 2d. 3D assessment of the uterine cervix correlated with clinical examination in all cases. Further, confirmation of our results was done by obtaining information from the referring clinician on the operative findings and on the other imaging modalities.

Reabsorption anomaly of the uterus namely septate uterus was the highest in incidence accounting for about $50 \%$ of the total uterine anomalies detected. Two of the septate uteri with double ostia were reported as unicornuate uterus on HSG as the dye injected had passed through only one ostium (Figure 3). Both of these patients had been evaluated for recurrent pregnancy loss and had three successive abortions. Ultrasound evaluation revealed a bifid endometrial cavity and 3D ultrasound clearly depicted that it was a septate uterus and not unicornuate uterus which was misinterpreted in HSG (Figure 3d).
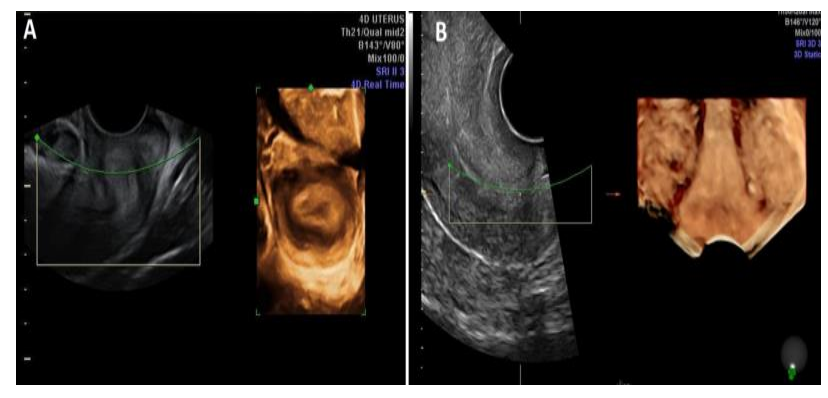

Figure 1: (A) Transverse rendered view of cervix (B) Longitudinal rendered image of cervix.
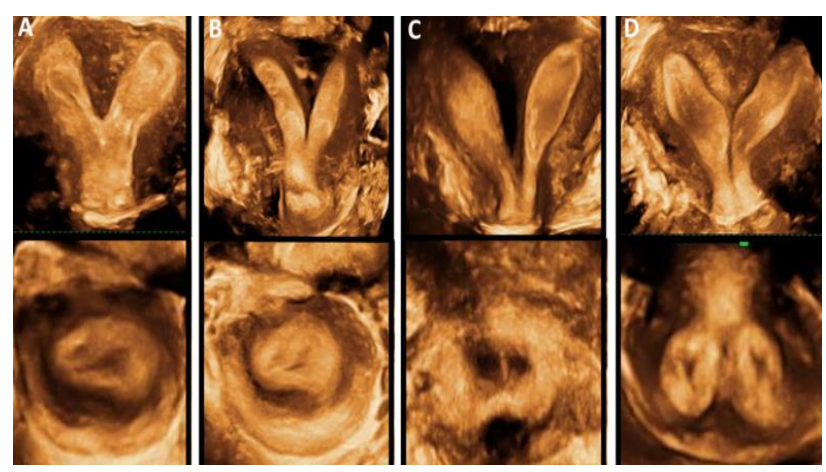

Figure 2: Four cases of septate uteri with their corresponding cervices (A) and (B) Septate uterus with partial septum and single ostium (C) Complete septum with double ostia (D) Septate uterus with duplicated cervix.

\section{DISCUSSION}

Mullerian ducts fuse normally between the 6th and 11th weeks of gestation to form the uterus, fallopian tubes, cervix, and proximal two-thirds of the vagina. ${ }^{5}$ Any disruption in this development either in the fusion or septal resorption during embryogenesis results in mullerian duct anomalies (MDA). Renal anomalies 
like renal agenesis, ectopic kidney, horseshoe kidney, duplicated collecting systems etc. occur in $30-50 \%$ of MDA. ${ }^{6}$ Other anomalies seen in association are that of the vertebral bodies (29\%) like wedged or fused vertebral bodies, cardiac anomalies (14.5\%), and syndromes such as Klippel-Feil syndrome (7\%).,

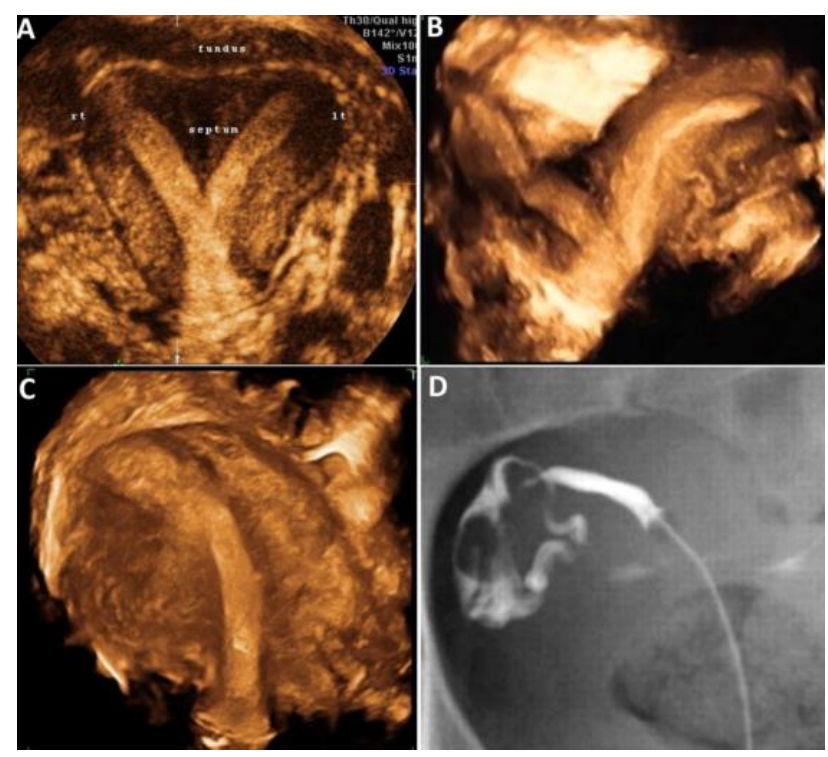

Figure 3: (A) 3D image of septate uterus (B) 3D image of bicornuate uterus $(C)$ 3D image of unicornuate uterus (D) HSG image in septate uterus misinterpreted as unicornuate uterus (dye filling only in one uterine cavity).
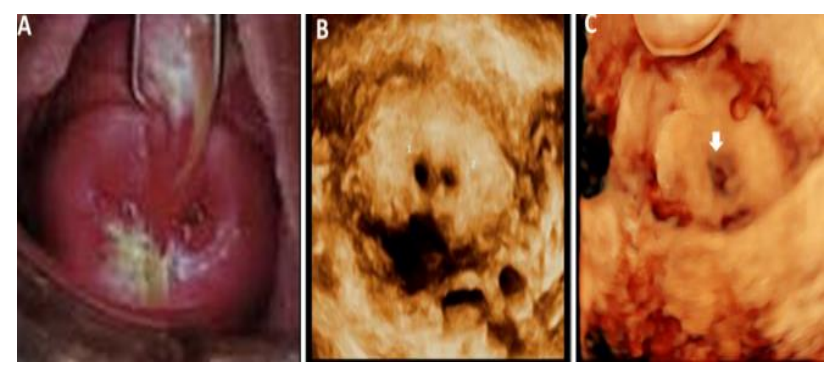

Figure 4: (A) Per speculum view of cervix (reproduced with permission from Ludwin et al (B) 3D image of cervix showing double ostia (C) 3D image (HD live) of cervix showing single ostium.

The most accepted classification for Mullerian duct anomalies (MDA) is that established by American Fertility Society (AFS) in $1988 .^{9}$ MDAs are classified into seven basic groups: 1) agenesis and hypoplasia, (2) unicornuate uteri, (3) didelphys uteri, (4) bicornuate uteri, (5) septate uteri, (6) arcuate uteri, and (7) anomalies related to diethylstilboestrol exposure. Though there are a lot of other variants reported in literature, many have not been still incorporated in the classification systems. A complete septum with a duplicated cervix is not included in class V ASRM. Accurate diagnosis of the type of uterine anomalies has clinical importance with respect to obstetric complications associated with it. ${ }^{10}$ MDA can present with infertility, recurrent pregnancy losses, endometriosis, fetal intrauterine growth restriction, fetal malposition, preterm labour, and retained placenta. ${ }^{11}$

HSG is the traditional method used to assess the uterus in routine infertility workup. With the use of contrast medium and radiation, it aids in assessing the uterine cavity and tubal patency. It is an invasive procedure that requires the presence of a gynaecologist or a radiologist or sometimes an anaesthesiologist. Saravelos et al in their review reported HSG's sensitivity, specificity, and accuracy in diagnosing uterine anomalies to be 78,90 , and $86 \%$, respectively (weighted mean of 9 studies). ${ }^{3}$ With a good quality HSG, though accurate information about uterine cavity can be obtained it cannot evaluate the external contour of the uterus. Septate, bicornuate and uterus didelphys have double uterine cavity and may appear similar in HSG. Visualization of external fundal contour is only possible with $3 \mathrm{D}$ ultrasound which aids in differentiating these uterine anomalies (Figure 3). In septate uterus, the external shape of the uterus is a single unit (Figure 3a), in bicornuate uterus there is branching of uterus into two distinct horns (Figure 3b) and whereas in uterus didelphys there are two separate uteri. The typical banana shaped uterus seen in 3D ultrasound is diagnostic of unicornuate uterus (figure 3c). In cases of complete septate uterus with a divided cervical canal, dye may not reach the other half resulting in misdiagnosis as unicornuate uterus in HSG (Figure 3d). Hence, the distinction between septate, unicornuate or bicornuate uterus is difficult using HSG as discussed above. ${ }^{12}$

The most important advantage of 3D US for diagnosing uterine anomalies are its ability to obtain a coronal view of the uterus, which is most often not possible in 2D US. This view clearly outlines the external contour of the uterus, as well as provides accurate information about the shape of the uterine cavity. ${ }^{12,13}$ It replaces the need for invasive diagnostic hysterolaparoscopic procedures and the surgeon can plan directly a therapeutic procedure as shown by El Huseiny et al in their study. ${ }^{1}$

Septate uterus is the most common among the Mullerian anomalies as reported by Chan et al and is also evident from our study results. ${ }^{14}$ The septum originates from the uterine fundus and is formed due to complete or partial failure of its resorption. A partial septate uterus presents with incompletely divided uterine cavity and a single cervix with a single ostium (Figures $2 \mathrm{a}$ and $\mathrm{b}$ ). In complete septate uterus, the septum extends from the fundus up to the cervix presenting as either a septate cervix with double ostia (Figure 2c) or a duplicated cervix (Figure 2d). Both may be seen in combination with or without a vaginal septum. ${ }^{4,15-17}$

With the help of 3D ultrasound the cervical os can be visualised as per speculum examination (Figure 4). This is extremely useful in patients with vaginal septum where despite insertion of a speculum the cervix is inadequately visualised. Ludwin et al have described in their paper the 
technique of using two sets of speculum to clearly visualise the double cervix in presence of a vaginal septum. He has stated that resection of vaginal septum helps in accurately identifying the double cervix (Figure 4a). ${ }^{15}$ We could clearly visualise the double cervix with transvaginal 3D ultrasound even without vaginal septal resection (Figure $4 \mathrm{~b}$ ). The ability of $3 \mathrm{D}$ ultrasound in delineating the extent of the dividing uterine septum and the division of cervical canal aids in the precise diagnosis of uterine anomaly.

Assessment of double uterine cavitary abnormalities is thus complete with 3D evaluation of cervix. The advantage in 3D US is the per speculum view of the cervix which can distinguish between single and double cervical ostium (Figures $4 \mathrm{~b}$ and $\mathrm{c}$ ). Over time, it is possible that 3D US may become the gold standard in diagnosing uterine anomalies. Hysteroscopy and laparoscopy may then be used only for therapeutic indications. ${ }^{13}$ Implementation of $3 \mathrm{D}$ ultrasound in routine workup of infertility would improvise in optimising the appropriate surgical correction and further would improve intraoperative orientation. Ludwin et al used real-time 3D transrectal US during hysteroscopic metroplasty for assessing the length of uterine septum left behind. ${ }^{18}$ This helps in preventing overzealous incisions and reduces the risk of incomplete septal resection.

Though operative hysterolaparoscopy and MRI are still the gold standard and helps in the complete diagnosis, 3D ultrasound is evolving as a powerful alternative imaging modality with a high level of diagnostic accuracy and reproducibility. ${ }^{19-22}$ Hysterolaparoscopy is an invasive procedure done under anaesthesia whereas MRI is expensive, time consuming, and not widely available. The presence of nearby bowel movements and a retroflexed uterus hinders MRI evaluation. ${ }^{23}$ It cannot always be interpreted by a radiologist experienced in uterine anomalies, which can reduce its accuracy. ${ }^{24}$ The ability to differentiate external uterine contour and myometrium by $3 \mathrm{D}$ ultrasound is equivalent to MRI and therefore is likely to replace MRI as the diagnostic modality of choice. ${ }^{25}$

To summarise, 3D US is a highly sensitive and specific tool for accurately diagnosing congenital uterine anomalies. It is non-invasive, fast, reproducible, readily available, relatively cost-effective tool and has now surpassed other modalities in the detection of congenital mullerian duct anomalies. ${ }^{2,13,26}$ Though the advantage of $3 \mathrm{D}$ ultrasound is well documented in the past, it has not been put in routine practice for the workup of infertility and recurrent pregnancy loss. This paper apart from giving the significance of transvaginal 3D ultrasound in detecting uterine anomalies, it also highlights the 3D transvaginal assessment of cervix in double uterine cavitary abnormalities. This would provide clinicians clarity in offering appropriate treatment options or referral to higher centres for advanced surgeries when necessary. We recommend the routine use of 3D ultrasound in the diagnostic workup of infertility and recurrent pregnancy loss; thereby the need for a diagnostic hysterolaparoscopy can virtually be eliminated in the near future.

Patient consent was obtained prior to the study and patient identity not disclosed.

\section{ACKNOWLEDGEMENTS}

Authors acknowledge the referring clinicians from whom the follow up was obtained.

Funding: No funding sources Conflict of interest: None declared

Ethical approval: Not required

\section{REFERENCES}

1. El Huseiny AM, Ahmad RA, Sadek SM, Gouhar GK, Dawood HA. Role of three-dimensional ultrasound in the diagnosis of double uterine cavity anomalies and concordance with laparoscopic and hysteroscopic diagnosis. The Egyptian Journal of Radiology and Nuclear Medicine. 2014;45(2):55560.

2. Dewan KA, Hefeda MM, ElKholy DG. Septate or bicornuate uterus: Accuracy of three-dimensional trans-vaginal ultrasonography and pelvic magnetic resonance imaging. The Egyptian Journal of Radiology and Nuclear Medicine. 2014;45(3):98795.

3. Saravelos SH, Cocksedge KA, Li TC. Prevalence and diagnosis of congenital uterine anomalies in women with reproductive failure: a critical appraisal. Hum Reprod Update. 2008;14:415-29.

4. Ribeiro SC, Yamakami LY, Tormena RA, Pinheiro WD, Almeida JA, Baracat EC. Septate uterus with cervical duplication and longitudinal vaginal septum. Revista da Associação Médica Brasileira. 2010;56(2):254-6.

5. Troiano RN, McCarthy SM. Mullerian duct anomalies: imaging and clinical issues. Radiology. 2004;233(1):19-34.

6. Li S, Qayyam A, Coakley FV, Hricak H. Association of renal agenesis and Müllerian duct anomalies. J Comput Assist Tomogr. 2000;6:829-34.

7. Kimberley N, Hutson JM, Southwell BR, Grover SR. Vaginal agenesis, the hymen, and associated anomalies. J Pediatr Adolesc Gynecol. 2012;25(1):54-8.

8. Gell JS. Müllerian anomalies. Semin Reprod Med. 2003;21(4):375-88.

9. American Fertility Society. The American Fertility Society classifications of adnexal adhesions, distal tubal occlusion, tubal occlusion secondary to tubal ligation, tubal pregnancies, müllerian anomalies and intrauterine adhesions. Fertil Steril. 1988;49:944-55. 
10. Bocca SM, Abuhamad AZ. Use of 3-dimensional sonography to assess uterine anomalies. Journal of Ultrasound in Medicine. 2013;32(1):1-6.

11. Devi Wold AS, Pham N, Arici A. Anatomic factors in recurrent pregnancy loss. Semin Reprod Med. 2006;24(1):25-32.

12. Woelfer B, Salim R, Banerjee S, Elson J, Regan L, Jurkovic D. Reproductive outcomes in women with congenital uterine anomalies detected by threedimensional ultrasound screening. Obstet Gynecol. 2001;98:1099-103.

13. Turkgeldi E, Urman B, Ata B. Role of ThreeDimensional Ultrasound in Gynecology. The Journal of Obstetrics and Gynecology of India. 2015;65(3):146-54.

14. Chan YY, Jayaprakasan K, Zamora J, Thornton JG, Raine-Fenning N, Coomarasamy A. The prevalence of congenital uterine anomalies in unselected and high-risk populations: a systematic review. Hum Reprod Update. 2011;17:761-71.

15. Ludwin A, Ludwin I, Pityński K, Banas T, Jach R. Differentiating between a double cervix or cervical duplication and a complete septate uterus with longitudinal vaginal septum. Taiwanese Journal of Obstetrics and Gynecology. 2013;52(2):308-10.

16. Practice Committee of the American Society for Reproductive Medicine. Uterine septum: a guideline. Fertility and sterility. 2016.

17. Barbanti S, Chiamulera N, Botelho B. Vaginal Septoplasty in Septate Uterus with Double Cervix. Case reports in obstetrics and gynecology. 2014.

18. Ludwin A, Ludwin I, Pityński K, Banas T, Jach R. Role of morphologic characteristics of the uterine septum in the prediction and prevention of abnormal healing outcomes after hysteroscopic metroplasty. Human Reproduction. 2014;29(7):1420-31.

19. Jurkovic D, Geipel A, Gruboeck K, et al. Threedimensional ultrasound for the assessment of uterine anatomy and detection of congenital anomalies: a comparison with hysterosalpingography and two dimensional sonography. Ultrasound Obstet Gynecol. 1995;5:233-7.

20. Salim R, Jurkovic D. Assessing congenital uterine anomalies: the role of thee-dimensional ultrasonography. Best Pract Res Clinical Obstet Gynecol. 2004;18:29-36.

21. Ghi T, Casadio P, Kuleva M. Accuracy of threedimensional ultrasound in diagnosis and classification of congenital uterine anomalies. Fertil Steril. 2009;92:808-13.

22. Salim R, Woelfer B, Backos M, Regan L, Jurkovic D. Reproductibility of three-dimensionnal ultrasound diagnosis of congenital uterine anomalies. Ultrasound Obstet Gynecol. 2003;21:578-82.

23. Armstrong L, Fleischer A, Andreotti R. Threedimensional volumetric sonography in gynecology: an overview of clinical applications. Radiologic Clinics of North America. 2013;51(6):1035-47.

24. Faivre E, Fernandez H, Deffieux X, Gervaise A, Frydman R, Levaillant JM. Accuracy of threedimensional ultrasonography in differential diagnosis of septate and bicornuate uterus compared with office hysteroscopy and pelvic magnetic resonance imaging. Journal of minimally invasive gynecology. 2012;19(1):101-6.

25. Deutch TD, Abuhamad AZ. The role of 3dimensional ultrasonography and magnetic resonance imaging in the diagnosis of Müllerian duct anomalies. J Ultrasound Med. 2008;27:413-23.

26. Bermejo C, Martínez Ten P, Cantarero R, Diaz D, Pérez Pedregosa J, Barrón E. Three-dimensional ultrasound in the diagnosis of Müllerian duct anomalies and concordance with magnetic resonance imaging. Ultrasound in Obstetrics and Gynecology. 2010;35(5):593-601.

Cite this article as: Lakshmy SR, Rose N, Ramachandran M. Role of three dimensional ultrasound in uterine anomalies - 3D assessment of cervix in septate uteri. Int J Reprod Contracept Obstet Gynecol 2016;5:3563-7. 